\title{
Reactivity of Half Esters of Polyhydric Alcohol with Amine
}

\author{
Hiroyuki Nakamura, Hiroyuki Sakuma, and Naoya Ogata \\ Department of Chemistry, Sophia University, \\ 7 Kioi-cho, Chiyoda-ku, Tokyo 102, Japan.
}

(Received May 22, 1978)

\begin{abstract}
The reaction of half esters derived from polyhydric alcohols including ethylene glycol or glycerol has been investigated. The reactivity of half esters toward the reaction with primary amine has been compared with the reactivity of ordinary esters. The reaction was enhanced by introducing hydroxyl groups into the alcohol moiety of esters, and it took place in solutions under mild conditions. The reactivity enhancement was related with the number of hydroxyl groups in the half esters; the half ester derived from glycerol reacted easily with amine with a much faster rate than ordinary esters. The reactivity enhancement owing to the hydroxyl group is explained by an interaction of the hydroxyl group with amine in solutions. A tentative experiment was carried out to prepare polyamide under mild conditions by using bis(2-hydroxyethyl) terephthalate.

KEY WORDS Aminolysis / Half Ester / Amine / Polycondensation /

Polyamide /
\end{abstract}

Numerous reports on the aminolysis reaction of esters with amines have been published in terms of the formation of amide compounds and reaction mechanisms have been proposed by many investigators. ${ }^{1}$ On the other hand, the reaction of esters with amine has not yet been systematically investigated in terms of the structural effect on the reactivity of esters with amines. A previous paper ${ }^{2}$ described the aminolysis reaction of diesters having hydroxyl groups in acyl moiety, which leads to an easy preparation of polyamide under mild conditions.

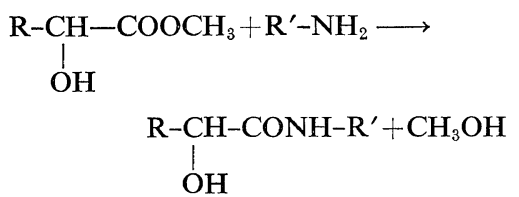

It is well known ${ }^{3,4}$ that the reactivity of esters with amines to form amide compounds can be also greatly enhanced by using so-called active esters, which are derived from more acidic alcohols. For instance, esters derived from phenol, ${ }^{5}$ thiophenol, ${ }^{6}$ or heterocylic alcohols ${ }^{7}$ can easily react with amine owing to the inductive effect of the alcohol moiety of the ester, which increases the susceptibility of the acyl-oxygen bond of the ester group toward the nucleophilic attack of amine in solutions.

The high reactivity of hydroxyl esters with amine was explained in a previous paper ${ }^{2}$ : an interaction between hydroxyl and amino groups may enhance the exchange reaction to form an amide linkage, presumably owing to an increase in the local concentration of a reaction intermediate which is favorable to an easy collision of ester with amine. If hydroxyl group in the ester plays an important role in the amide-forming reaction owing to an interaction with the approaching amine, it is expected that half esters derived from polyhydric alcohols may easily react with amine to form an amide linkage under mild conditions, with a rate as fast as the reaction of hydroxyl esters which contain hydroxyl group in acyl moiety. Therefore, various half esters from polyhydric alcohols have been synthesized and their reactivity toward amine has been investigated in terms of the formation of amide compounds.<smiles>[R]CNNCCCC([R])=O</smiles> 
It is also presumed ${ }^{8}$ that the formation of polypeptide from $\alpha$-amino acids may proceed through the formation of $\alpha$-amino acid esters derived from saccharides such as ribose, which are polyhydric alcohols. Therefore, the reactivity of half esters derived from polyhydric alcohols toward amine may provide us with a key to solve questions related with the synthetic route of polypeptide in a living body. This paper aims at the elucidation of the reactivity of half esters derived from polyhydric alcohols toward the reaction with primary amine in solutions. We also tentatively tried to prepare polyamide in solution under mild conditions by using diesters from polyhydric alcohols.

\section{EXPERIMENTAL}

Synthesis of Half Esters from Aliphatic Polyhydric Alcohol

The following half esters were synthesized.

1. 2-Hydroxyethyl butyrate (EGB), $\mathrm{C}_{3} \mathrm{H}_{7} \mathrm{COOCH}_{2} \mathrm{CH}_{2} \mathrm{OH}$ bp $57-60^{\circ} \mathrm{C} / 0.1 \mathrm{mmHg}$, yield $47 \%$

2. 2-Hydroxypropyl butyrate (TGB), $\mathrm{C}_{3} \mathrm{H}_{7} \mathrm{COO}\left(\mathrm{CH}_{2}\right)_{3} \mathrm{OH}$ bp $74-76^{\circ} \mathrm{C} / 1 \mathrm{mmHg}$, yield $64 \%$

3. 2,3-Dihydroxypropyl butyrate (GB), $\mathrm{C}_{3} \mathrm{H}_{7} \mathrm{COOCH}_{2} \mathrm{CHCH}_{2} \mathrm{OH}$ OH

bp $96-98^{\circ} \mathrm{C} / 0.06 \mathrm{mmHg}$, yield $69 \%$

4. 2,3-Dihydroxypropyl benzoate (G-Ar),<smiles>O=C(OCC(O)CO)c1ccccc1</smiles>

bp $155-156^{\circ} \mathrm{C} / 0.3 \mathrm{mmHg}$, yield $22 \%$

5. Bis(2-hydroxyethyl)terephthalate (BHT), $\mathrm{HOCH}_{2} \mathrm{CH}_{2} \mathrm{OCO}-\mathrm{COOCH}_{2} \mathrm{CH}_{2} \mathrm{OH}$ mp $109-111^{\circ} \mathrm{C}$, yield $25 \%$

Typical procedures for the synthesis are as follows: 2-hydroxyethyl butyrate (EGB) was synthesized by reacting an equimolar amount of butyryl chloride $(60 \mathrm{~g})$ with ethylene glycol $(40 \mathrm{~g})$ in tetrahydrofuran (THF, $500 \mathrm{ml})$ in the presence of triethylamine $(58 \mathrm{~g})$. After removing the triethylamine salt by filtration and evaporating the THF, a residual oil was distilled in vacuum. 2-hydroxypropyl butyrate (TGB) was obtained by the same procedure.

2,3-Dihydroxypropyl butyrate (GB) was syn- thesized by reacting sodium butyrate $(64 \mathrm{~g})$ with 3-chloro-1, 2-propanediol (60 g) in $N, N^{\prime}$-dimethylformamide (DMF, $500 \mathrm{ml}$ ) at $60^{\circ} \mathrm{C}$ for $24 \mathrm{~h}$. After filtering the potassium chloride and evaporating the DMF in vacuum, GB was obtained by vacuum distillation. 2,3-Dihydroxypropyl benzoate (G-Ar) was obtained by a similar procedure.

Bis(2-hydroxyethyl) terephthalate (BHT) was synthesized by the transesterification of dimethyl terephthalate with two times the number of moles of ethylene glycol. ${ }^{9}$ It was purified by repeated recrystallizations from a mixture of water and ethanol.

All of these obtained half esters were identified by elemental, infrared, and NMR analyses, and their purities were confirmed by gas chromatography.

\section{Synthesis of Half Esters from Aromatic Polyhydric Alcohol}

Aromatic half esters from benzoic acid and polyhydric phenols were synthesized by reacting benzoyl chloride with polyhydric phenols, such as pyrocatechol or resorcinol. For instance, 2hydroxyphenyl benzoate (2-HPB) was obtained by reacting $22 \mathrm{~g}$ of pyrocatechol with $28 \mathrm{~g}$ of benzoyl chloride in $200 \mathrm{~m} l$ of THF in the presence of $22 \mathrm{~g}$ of triethylamine. After refluxing the solution for $3 \mathrm{~h}$, triethylamine salt was filtered off and THF was evaporated. A residual solid was extracted with ether. The ether solution was dried over anhydrous magnesium sulfate and the ether was evaporated. 2-HPB was purified by recrystallization from benzene.

1. Phenyl benzoate: $\mathrm{mp} 65.5^{\circ} \mathrm{C}$.

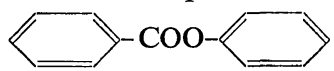

2. 2-Hydroxyphenyl benzoate (2-HPB):

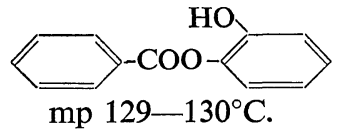

3. 3-Hydroxyphenyl benzoate (3-HPB):

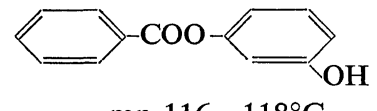

mp $116-118^{\circ} \mathrm{C}$.

4. 2-Methyl-3-hydroxyphenyl benzoate (MHP):

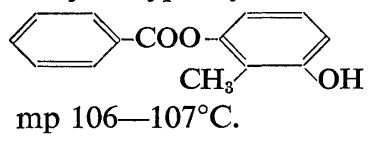

Polymer J., Vol. 11, No. 4, 1979 


\section{Reaction of Ester with Amine}

Equimolar amounts of aliphatic half esters and butylamine were dissolved in various solvents at a given concentration and the solutions were stirred at a constant temperature. Rates of the reaction were determined by measuring the residual amounts of amine in the solution by means of a back-titration method with $0.5-\mathrm{N} \mathrm{HCl}$.

Rates of the reaction of aromatic half esters were determined by measuring the total amount of the amide formed. Liquid chromatography using the Waters high-speed liquid chromatography model-440 was employed under following conditions:

Column: micropolasil $\mu-\mathrm{NH}_{2}$

Solvent: $n$-hexane-tetrahydrofuran (3:2)

Flow rate: $1.5 \mathrm{ml} / \mathrm{min}$

Detector: UV at $254 \mathrm{~nm}$

Polycondensation reactions of BHT with hexamethylenediamine were carried out at 60 or $100^{\circ} \mathrm{C}$ in a monomer concentration of $0.5 \mathrm{~mol} / l$. The resulting polyamide was collected by pouring the solution into excess acetone, then filtering and washing with acetone; it was finally dried in vacuum.

\section{RESULTS AND DISCUSSION}

\section{Aliphatic Half Esters}

The reaction of various half esters with butylamine was carried out in $\mathrm{N}, \mathrm{N}$-dimethylacetamide (DMAc) at $60^{\circ} \mathrm{C}$ in the concentration of $1 \mathrm{~mol} / l$. The results are indicated in Figure 1, where it is seen that the reactivity of these half esters is enhanced by substituting a hydroxyl group in the alcohol moiety of esters. Rates of the reaction

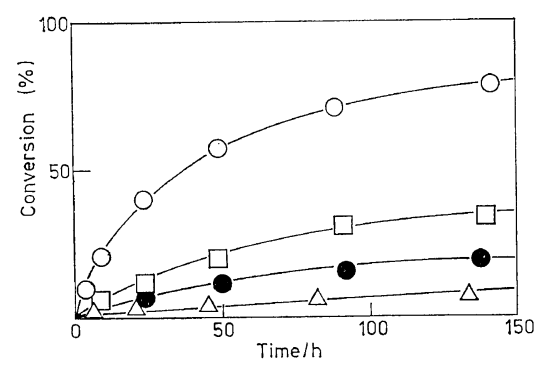

Figure 1. Reaction of various butyrates with butylamine in DMAc: concn of ester and amine $=1 \mathrm{~mol} / l$; temp $=60^{\circ} \mathrm{C} ; \mathrm{O}, \mathrm{GB} ; \square, \mathrm{EGB} ; \odot$, TGB; $\triangle$, EB. increased with increasing numbers of hydroxyl groups in the alcohol moiety of the ester group. As shown in Figure 1, the reaction of EGB was faster than that of TGB; the distance between ester and hydroxyl groups also had an influence on the reactivity enhancement for the reaction to form amide.

Figure 2 indicates the reaction of GB in various solvents. Here it is seen that the aminolysis reaction proceeds rapidly in aprotic polar solvents such as DMAc, while it takes place rather slowly in protic solvents like methanol. These results indicate that the reactions of half ester are influenced not only by the polarity of solvents, but also by the hydroxyl group of solvents. As described before, the hydroxyl group of half esters enhanced the reactivity toward the aminolysis reaction which is reduced by methanol. The reason for this may be an interaction of amine with the hydroxyl groups of either half ester or methanol as a solvent. In methanol, the interaction between the hydroxyl group of methanol and amine may be stronger than that between the hydroxyl group of half ester and amine, thus reducing the enhancement effect for the reaction.

The reaction of $\mathrm{G}-\mathrm{Ar}$, which is an aromatic half ester, was carried out in various solvents. Results are shown in Figure 3, which indicates almost the same tendency of the solvent effect as that of GB. On the other hand, solvents did not influence the rate of the reaction of EGB or ethyl butyrate, which is an ordinary ester.

Summarizing these results, the reactivity enhancement of these half esters may be ascribed to an intermolecular interaction between the hydroxyl

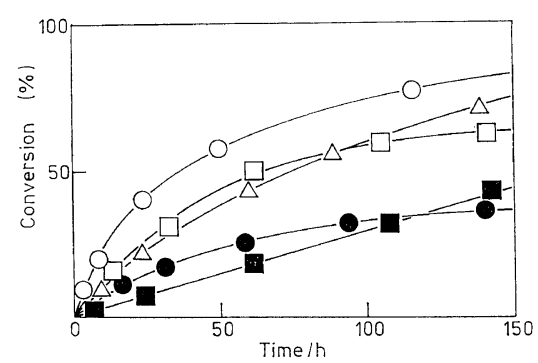

Figure 2. Reaction of GB with butylamine in various solvents at $60^{\circ} \mathrm{C}$ : concn of ester and amine $=1 \mathrm{~mol} / l$; $\bigcirc$, DMAc; $\square$, acetonitrile; $\triangle$, dimethylsulfoxide; $\boldsymbol{O}$, methanol; $\mathbf{\square}$, dioxane. 


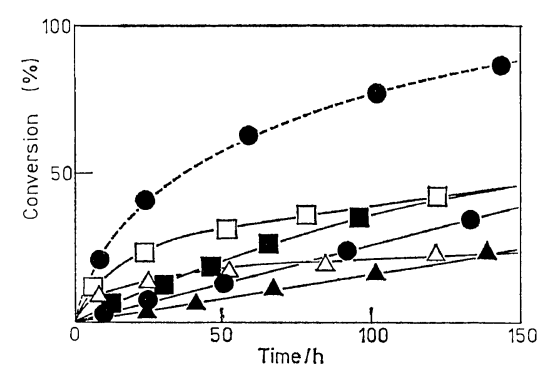

Figure 3. Reaction of G-Ar with butylamine in various solvents: concn of ester and amine $=1 \mathrm{~mol} / l$, temp $=60^{\circ} \mathrm{C} ; \square$, dimethylsulfoxide; $\mathbf{\square}$, acetonitrile; $\triangle$, methanol; $\odot$, DMAc; $\mathbf{\Delta}$, dioxane; -----, reaction of GB in DMAc.

group of the half esters and amine, as was postulated in the case of hydroxyl ester in a previous paper. $^{2}$

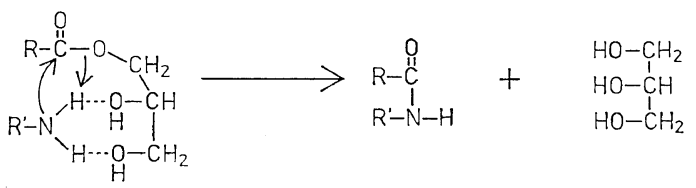

Since the carbonyl absorption of GB, G-Ar, EGB, or ethyl butylate appeared at the same position around $1725 \mathrm{~cm}^{-1}$ in their infrared spectra, the electron density of the carbonyl group of these half esters is not significantly different from that of ordinary esters. Thus the reactivity change of these half esters may be caused by the difference in the interaction of the hydroxyl group with the amine approaching at the intermediate stage of the reaction.

The reaction of these half esters in DMAc was kinetically analyzed by changing the conditions in solutions, including concentrations or temperatures, and apparent rate constants were determined; these are summarized in Table I.

Table I. Amidation reaction of various half esters with butylamine in DMAc

\begin{tabular}{cccc}
\hline Half ester & $\begin{array}{c}k_{0} \text { at } 60^{\circ} \mathrm{C}, \\
l / \mathrm{mol}, \mathrm{s}\end{array}$ & $\begin{array}{c}\text { Apparent } \\
\text { order of } \\
\text { reaction }\end{array}$ & $\begin{array}{c}\text { Activation } \\
\text { energy, } \\
\mathrm{kcal} / \mathrm{ml}\end{array}$ \\
\hline GB & $5.4 \times 10^{-6}$ & 3.1 & 8.1 \\
EGB & $2.2 \times 10^{-6}$ & 2.2 & 8.4 \\
EB & $2.1 \times 10^{-7}$ & 1 & 14 \\
\hline
\end{tabular}

The equimolar reaction of half ester and amine is expressed in the following equation

$$
a \mathrm{~A}+b \mathrm{E} \stackrel{k}{\longrightarrow} \text { Amide }+ \text { Alcohol }
$$

where $\mathrm{A}$ and $\mathrm{E}$ represent amine and half ester and $a, b$ denote moles of reactants. The rate $v$ of the reaction can be expressed as follows

$$
v=k C_{\mathbf{\Delta}}{ }^{a} C_{\mathbf{E}}{ }^{b}
$$

where $C$ represents concentration. Since the initial concentration $C_{\mathrm{A}_{0}}=C_{\mathrm{E}_{0}}, v_{0}$, which is obtained by extrapolating $v$ to $t=0$, can be expressed as follows.

$$
v_{0}=k_{0} C_{A_{0}}^{a+b}
$$

By plotting $\log v_{0}$ against $\log C_{\mathbf{A}_{0}}$, a linear relationship was found, and $k_{0}$ and $(a+b)$, which is the order of the reaction, were determined from the intercept and slope of the line. Results are listed in Table I.

The reaction of GB took place in a third ordered reaction, while that of EGB or EB apparently proceeded in second or first orders. Activation energies of the reaction of these half esters are arranged in the following order: $\mathrm{GB}<\mathrm{EGB} \ll \mathrm{EB}$. The lower activation energy of the reaction of half esters may also indicate the existence of an interaction of the hydroxyl group of the half esters with amine.

\section{Aromatic Half Esters}

As shown in Figure 3, the reaction of G-Ar takes place more slowly than that of GB, which is an aliphatic half ester, although the reaction of G-Ar occurs with a faster rate than that of ordinary esters such as ethyl benzoate. The lower reactivity of G-Ar may be ascribed to a conjugated system of the ester carbonyl group toward the nucleophilic attack of amine. Therefore, the aminolysis reaction of benzoate derived from aromatic polyhydric alcohols such as pyrocatechol or resorcinol was carried out in order to investigate the reactivity enhancement owing to hydroxyl groups of aromatic half esters.

The aminolysis reaction of 2-HPB, 3-HPB, or MHP with butylamine was carried out in dioxane at $35^{\circ} \mathrm{C}$ under the same conditions as described in a previous paper ${ }^{2}$ and the reactions were analyzed to determine apparent rate constants $k_{\text {obs }}$. As mentioned in the previous paper, the aminolysis 
reaction of ester is accelerated by an autocatalytic effect of amine itself and the value of $k_{\text {obs }}$ can be divided into two terms because a large excess of amine was used.

$$
k_{\text {obs }}=k_{1}[\text { Amine }]+k_{2}[\text { Amine }]^{2}
$$

Values of $k_{1}$ and $k_{2}$ were determined according to the same method as described in the previous paper; they are summarized in Table II. As shown in Table II, 2-HPB had the highest rate constant among these aromatic half esters. The enhancement effect caused by the hydroxyl group of 2-HPB may be related with the ortho effect, as was reported for the hydrolysis ${ }^{10}$ of pyrocatechol monobenzoate.<smiles></smiles>

Table II. Aminolysis reaction of aromatic half esters with butylamine ${ }^{a}$

\begin{tabular}{|c|c|c|c|c|}
\hline $\begin{array}{l}\text { Half ester of } \\
\text { benzoic acid }\end{array}$ & $\begin{array}{l}c_{\mathrm{I}} \\
\mathrm{m}\end{array}$ & ol & $\begin{array}{c}k_{1} \\
\mathrm{~mol}^{-1}, \mathrm{~s}^{-1}\end{array}$ & $\begin{array}{c}k_{2} \\
\mathrm{~mol}^{-1}, \mathrm{~s}^{-1}\end{array}$ \\
\hline$-0-0$ & 1.12 & $<10^{-2}$ & $7.46 \times 10^{-6}$ & $1.00 \times 10^{-5}$ \\
\hline $\begin{array}{l}-0-0> \\
\mathrm{HO}\end{array}$ & 1.02 & $"$ & $2.24 \times 10^{-3}$ & $2.61 \times 10^{-4}$ \\
\hline$-0-\left\langle\mathrm{a}_{\mathrm{OH}}\right.$ & 1.07 & " & " & $1.91 \times 10^{-4}$ \\
\hline${ }_{\mathrm{H}_{3} \mathrm{C}} \mathrm{CO}_{\mathrm{OH}}$ & 1.03 & $" \prime$ & $1.97 \times 10^{-5}$ & $1.87 \times 10^{-5}$ \\
\hline
\end{tabular}

a Temp, $35^{\circ} \mathrm{C}$.

b Initial concentration of half ester.

Although a direct comparison of apparent rate constants is not reasonable because of the difference in reaction conditions, aromatic half esters react much faster with amine than do aliphatic half esters. Perhaps this may be ascribed to the inductive effect of phenol. ${ }^{5}$

Figure 4 indicates the reaction of BHT with butylamine in dimethylsulfoxide (DMSO) at $60^{\circ} \mathrm{C}$, in comparison with that of diethyl terephthalate. The reaction of BHT took place faster than that of diethyl terephthalate and the high reactivity of the aromatic half ester derived from

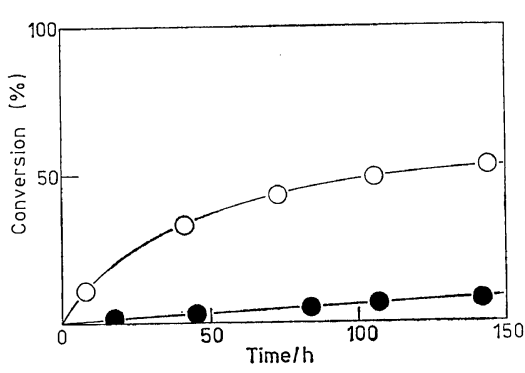

Figure 4. Reaction of BHT with butylamine in dimethylsulfoxide at $60^{\circ} \mathrm{C}$ : concn of diester $=1 \mathrm{~mol} / l$; concn of butylamine $=2 \mathrm{~mol} / l ; O, \mathrm{BHT} ; \odot$, diethyl terephthalate.

ethylene glycol was again confirmed in the case of the diester.

The reaction of BHT was extended to prepare polyamide under mild conditions. Results are summarized in Table III. As the polycondensation reaction of $\mathrm{BHT}$ with hexamethylenediamine proceeded in a heterogeneous phase where the resulting polymer started to precipitate out of the solution, the resulting polyamides were not satisfactory in terms of polymer yields and solution viscosities. Further investigations on the optimum reaction conditions are necessary to prepare polyamide having a high molecular weight by using diesters derived from polyhydric alcohols.

Table III. Polycondensation of BHT with hexamethylenediamine in solutions

\begin{tabular}{|c|c|c|c|c|}
\hline \multirow{2}{*}{ Solvent ${ }^{\mathrm{a}}$} & \multirow{2}{*}{$\underset{{ }^{\circ} \mathrm{C}}{\text { Temp, }}$} & \multirow{2}{*}{$\underset{\mathrm{h}}{\text { Time, }}$} & \multicolumn{2}{|c|}{ Polymer } \\
\hline & & & $\begin{array}{c}\text { Yield, } \\
\%\end{array}$ & $\eta_{\mathrm{sp}} / c^{\mathrm{b}}$ \\
\hline \multirow[t]{2}{*}{ Dimethylformamide } & 60 & 100 & 5 & - \\
\hline & 100 & 113 & 51 & 0.08 \\
\hline \multirow[t]{2}{*}{ Dimethylacetamide } & 60 & 100 & 5 & - \\
\hline & 100 & 113 & 49 & 0.08 \\
\hline \multirow{2}{*}{$\begin{array}{l}N \text {-Methyl- } \alpha- \\
\text { pyrrolidone }\end{array}$} & 60 & 110 & 13 & 0.09 \\
\hline & 100 & 239 & 65 & 0.10 \\
\hline
\end{tabular}

a Monomer concn, $0.5 \mathrm{~mol} / l$.

b Measured in sulfuric acid at $30^{\circ} \mathrm{C}$.

\section{REFERENCES}

1. W. P. Jencks, Chem. Rev., 72, 705 (1972).

2. N. Ogata, K. Sanui, and H. Nakamura, Polym. J., 10, 499 (1978). 
H. Nakamura, H. Sakuma, and N. Ogata

3. F. M. Menger and J. H. Smith, J. Am. Chem. Soc., 94, 3824 (1972).

4. H. D. Jakubke and A. Voigt, Chem. Ber., 99, 2419 (1966).

5. M. Hasegawa and Y. Suzuki, Kogyo Kagaku Zasshi, 68, 2441 (1965).

6. N. Ogata, K. Sanui, and K. Iijima, J. Polym. Sci. Polym. Chem. Ed., 11, 1095 (1973).

7. K. Sanui, S. Tanaka, and N. Ogata, J. Polym.
Sci., Polym. Chem. Ed., 15, 1107 (1977).

8. E. E. Conn and P. K. Stumpf, "Outlines of Biochemistry," John Wiley and Sons, Inc., New York, N.Y., 1963.

9. M. Sumoto and Y. Hasegawa, Kogyo Kagaku Zasshi, 68, 1693 (1965).

10. B. Capon and B. Ch. Ghosh, J. Chem. Soc. Sect. B, 472 (1966). 